\title{
Effect of quorum sensing and quenching molecules on inter-kingdom biofilm formation by Penicillium expansum and bacteria
}

\author{
Tiago Barros Afonso, Lúcia Chaves Simões and Nelson Lima
}

CEB, Centre of Biological Engineering, University of Minho, Braga, Portugal

ABSTRACT

The ecology of a biofilm is a complex function of different factors, including the presence of microbial metabolites excreted by the inhabitants of the biofilm. This study aimed to assess the effect of patulin, and $\mathrm{N}$-(3-oxododecanoyl)-L-homoserine lactone (3-oxo- $\mathrm{C}_{12}$-HSL) on inter-kingdom biofilm formation between a filamentous fungus and bacteria isolated from drinking water. The filamentous fungus Penicillium expansum and the bacteria Acinetobacter calcoaceticus and Methylobacterium oryzae were used as model species. M. oryzae biofilm formation and development was more susceptible to the presence of the quenching molecules than $A$. calcoaceticus biofilms. Patulin reduced $M$. oryzae biofilm growth while 3-oxo- $\mathrm{C}_{12}-\mathrm{HSL}$ caused an increase after $48 \mathrm{~h}$. The presence of $P$. expansum had a detrimental effect on $M$. oryzae cell numbers, while an advantageous effect was observed with $A$. calcoaceticus. The overall results reveal that quorum sensing and quenching molecules have a significant effect on inter-kingdom biofilm formation, especially on bacterial numbers.
ARTICLE HISTORY

Received 3 May 2020

Accepted 6 October 2020

\section{KEYWORDS}

Quorum sensing; quorum quenching; inter-kingdom interaction; biofilm mass; filamentous fungi; bacteria

\section{Introduction}

Drinking water distribution systems (DWDS) represent a system of reservoirs, pipes, and treatment facilities employed to transport water to the public and are known to harbour biofilms which in turn represent $>95 \%$ of the biomass in these systems (Flemming et al. 2002; Siqueira et al. 2013). Biofilms are responsible for influencing different factors affecting the quality of drinking water (DW). They can be a reservoir of pathogens and lead to an increase in cell numbers in the bulk phase, cause changes in the organoleptic properties of the water, and increase the corrosion rate of pipes and be responsible for the production of toxins (Paterson and Lima 2005; Feazel et al. 2009; Li et al. 2015; Wang et al. 2017; Zhou et al. 2017). Biofilm studies on DWDS have had bacteria as their main focus. However, an increasing number of studies have also been performed regarding total microbial ecology and, in particular, the presence and biofilm formation ability of filamentous fungi (Simões et al. 2015; Douterelo et al. 2016; Afonso et al. 2019; Fernandes et al. 2019). Due to their absorptive mode of nutrition, secretion of extracellular enzymes to digest complex molecules and their apical hyphal growth, these fungi have a high aptitude to grow on surfaces (Jones 1994). They can be introduced into DWDS from the water reservoirs as natural contaminants or other different locations, such as leaking joints and adapters, cracks in pipelines, physical openings in storage facilities and/or during maintenance. Fungi have also been associated with the production of mycotoxins in water (Paterson et al. 1997; 2007; Siqueira et al. 2013).

Under natural conditions, biofilms are considered complex communities with a high diversity of complex relationships involving inter- and intraspecies interactions (Douterelo et al. 2016; 2018). In many microbiomes bacteria can coexist with different eukaryotes, including fungi (Frey-Klett et al. 2011). These interactions can occur in biofilms. The ecology of a biofilm is dependent on a complex mix of prevailing growth conditions, hydrodynamic forces and the presence of microbial metabolites and molecules, including cell-cell signalling communication molecules excreted by the microbial inhabitants of the biofilm (Bryers and Ratner 2004). Quorum sensing (QS) is a mechanism employed by microbial species to coordinate community behaviour. It allows perception of population density by the production, release and detection of small signalling communication

CONTACT Nelson Lima nelson@ie.uminho.pt

(1) Supplemental material for this article can be accessed at https://doi.org/10.1080/08927014.2020.1836162.

(C) 2020 Informa UK Limited, trading as Taylor \& Francis Group 
molecules which in turn modify bacterial gene expression (Rasmussen et al. 2005a). In Gram-negative bacteria, the primary signalling molecules involved in QS mechanism are $\mathrm{N}$-acyl homoserine lactones (AHLs). These molecules differ in the length of their side chains (C4 to C19) (Churchill and Chen 2011; Saurav et al. 2020). The $N$-(3-oxododecanoyl)-L-homoserine lactone (3-oxo- $\mathrm{C}_{12}$-HSL) is considered a representative autoinducer-1, involved in the LasI/LasR system, the most common quorum sensing system in Gramnegative bacteria (Papenfort and Bassler 2016). QS controls and regulates different bacterial population density-dependent processes, including, biofilm formation, stress resistance, production of toxins and secondary metabolites and pathogenicity (Antunes et al. 2010; Shrout et al. 2011). In contrast, eukaryotes have the ability to interfere with bacterial communication by producing molecular signals that interact with bacterial QS. These compounds are called quorum sensing inhibitors (QSI) and they can mimic autoinducer structure or function, act as antagonists to the QS molecules, interfere with the stability and function of the regulator protein or the autoinducer synthase and hydrolysate signalling molecules (González and Keshavan 2006). Filamentous fungi, in particular the genus Penicillium, have been studied regarding their QSI potential (Rasmussen et al. 2005b). As they coexist with bacteria and do not have active immune systems, they must rely instead on chemical defence mechanisms. Patulin, a well-known polyketide fungal secondary metabolite (mycotoxin) with a low molecular weight $\left(154.12 \mathrm{~g} \mathrm{~mol}^{-1}\right)$ and a high polarity, is one of these biologically active QSI compounds (Rasmussen et al. 2005b).

As there is a gap in the study of the effects of the fungal secondary metabolite patulin and AHLs on inter-kingdom biofilm formation between filamentous fungi and bacteria, the purpose of this work was to assess, under laboratory conditions, the effect of patulin and 3-oxo- $\mathrm{C}_{12}$-HSL on single and inter-kingdom biofilm formation by a filamentous fungus and bacteria isolated from a DWDS.

\section{Materials and methods}

\section{Microorganisms and culture conditions}

Penicillium expansum MUM 00.02, supplied by Micoteca da Universidade do Minho fungal culture collection (MUM, Braga, Portugal), was used in this work and chosen based on its occurrence in the tap water in the north of Portugal and because it is able to form single and inter-kingdom biofilms (Gonçalves et al. 2006; Simões et al. 2015; Afonso et al. 2019). $P$. expansum was maintained on malt extract agar (MEA: malt extract $20 \mathrm{~g}$, peptone $5 \mathrm{~g}$, agar $20 \mathrm{~g}$, distilled water 11 ).

Acinetobacter calcoaceticus and Methylobacterium oryzae were previously isolated from a model laboratory DWDS by Simões et al. (2007b). These were chosen for being representative of drinking water bacteria and due to their ability to form complex single species biofilms as well as inter-kingdom biofilms with this fungus (Simões et al. 2010, Afonso et al. 2019). A. calcoaceticus was grown overnight while $M$. oryzae was grown for $72 \mathrm{~h}$ before the start of the assay. The bacteria were grown in batch cultures using $100 \mathrm{ml}$ of $\mathrm{R} 2 \mathrm{~A}$ broth (yeast extract $0.5 \mathrm{~g}$, proteose peptone $0.5 \mathrm{~g}$, casein hydrolysate $0.5 \mathrm{~g}$, glucose $0.5 \mathrm{~g}$, soluble starch $0.5 \mathrm{~g}$, dipotassium phosphate $0.3 \mathrm{~g}$, magnesium sulphate $0.024 \mathrm{~g}$, sodium pyruvate $0.3 \mathrm{~g}$, distilled water $1 \mathrm{l})$ at room temperature $\left(25 \pm 2{ }^{\circ} \mathrm{C}\right)$ and under agitation $(150 \mathrm{rpm})$. Afterwards, the bacteria were harvested by centrifugation (10 min at $13,000 \mathrm{~g}$, room temperature), washed twice in $0.1 \mathrm{M}$ saline phosphate buffer, and resuspended in a volume of R2A broth to obtain a cellular density of $10^{8}$ cells $\mathrm{ml}^{-1}$. This was the bacterial concentration used for biofilm formation assays.

\section{Stock solution of fungal spores}

A stock solution of fungal spores was prepared according to Simões et al. (2015). Briefly, spores of $P$. expansum were harvested from seven-day old pure cultures in MEA at $25^{\circ} \mathrm{C}$ by flooding the surface of the agar plates with $2 \mathrm{ml}$ of TWS solution $(0.85 \%$ $\mathrm{NaCl}$ plus $0.05 \%$ Tween 80 ) and rocking gently. The suspension was then homogenized by vortexing and used for large scale production of spores. The final spore suspension was homogenized by vortexing before quantification using a Neubauer count chamber. Aliquots of spore suspension with $10 \%$ of glycerol were cryopreserved at $-80^{\circ} \mathrm{C}$ in order to allow the use of the same spore suspension in all the biofilm assays. Stock spore suspensions were resuspended in the volume of $\mathrm{R} 2 \mathrm{~A}$ broth necessary to achieve a density of $10^{5}$ spores $\mathrm{ml}^{-1}$. This was the spore concentration used for biofilm formation assays. Assays were performed with germinated fungal spores. Spores were pre-germinated in order to stimulate their metabolic state. Germinated fungal spores were prepared by inoculating $10^{5}$ fresh spores $\mathrm{ml}^{-1}$ in R2A broth for $\sim 14 \mathrm{~h}$ (sufficient time to have $>95 \%$ spore germination). 
Preparation of quorum sensing and quenching molecules

Patulin and 3-oxo- $\mathrm{C}_{12}$-HSL were purchased from Cayman Chemical (Ann Arbor, MI, USA) and SigmaAldrich (St Louis, MO, USA) respectively. Stock solutions of $32.5 \mathrm{mM}$ were prepared for each individual molecule in dimethyl sulfoxide (DMSO) (Merck $\mathrm{KGaA}$, Darmstadt, Germany) and stored at $-20^{\circ} \mathrm{C}$ until use. From the original stock solutions, dose working solutions of 50 and $500 \mu \mathrm{M}$ were prepared using R2A broth.

\section{Determining the effect of quorum sensing and quenching molecules on biofilm formation}

Biofilms were developed according to the modified microtiter plate test used by Stepanović et al. (2000) for bacteria and Simões et al. (2015) for fungi. Briefly, for the single-species biofilms, wells of sterile polystyrene 96-well flat bottom culture plates (SARSTEDT AG \& Co. KG, Nümbrecht, Germany) were filled under aseptic conditions with $190 \mu \mathrm{l}$ of spore suspension $\left(10^{5}\right.$ spores $\mathrm{ml}^{-1}$ in R2A broth) or $190 \mu \mathrm{l}$ of a cell suspension $\left(10^{8}\right.$ cells $\mathrm{ml}^{-1}$ in $\mathrm{R} 2 \mathrm{~A}$ broth) supplemented with $10 \mu \mathrm{l}$ of each molecule dose working solution of 50 and $500 \mu \mathrm{M}$ to yield a final concentration of 2.5 and $25 \mu \mathrm{M}$, respectively. For inter-kingdom biofilm formation, $95 \mu \mathrm{l}$ of germinated fungal spore suspension and $95 \mu \mathrm{l}$ of the bacterial cell suspension were added to each well supplemented with $10 \mu \mathrm{l}$ of each molecule dose working solution. Positive controls were done by adding $10 \mu \mathrm{l}$ of the same amount of plain DMSO in R2A broth to each well. The reduction to half-cell density in the inter-kingdom assays was performed to avoid limitation of nutritional factors. $P$. expansum grew alongside each bacterium. To promote biofilm formation, all plates were incubated aerobically at room temperature $\left(25 \pm 2{ }^{\circ} \mathrm{C}\right)$ and under agitation $(150 \mathrm{rpm})$ for 24,48 and $72 \mathrm{~h}$. Biofilms at 48 and $72 \mathrm{~h}$ were considered as matured, well developed biofilms. Every $24 \mathrm{~h}$, depleted medium was removed and renewed with fresh, clean medium, supplemented with the respective concentration of each molecule. At each sampling time, the content of each well was removed and washed two times with $200 \mu \mathrm{l}$ of sterile distilled water to remove non-adherent and weakly adherent cells. The plates were air dried for $30 \mathrm{~min}$ to remove excess water by evaporation. The remaining attached cells were analysed in terms of biomass adhered on the inner walls of the wells, in terms of metabolic activity and colony forming units (CFU) for bacteria. The rinsing and drying procedures were as previously used with bacterial and fungal biofilms (Simões et al. 2007a; 2010; 2015; Afonso et al. 2019). Negative controls were obtained by incubating the wells with only R2A broth without adding any fungal spores or bacterial cells. Biofilm assays were performed three times with five replicates per experiment.

\section{Biofilm monitoring by spectrophotometric methods}

\section{Biofilm mass quantification by crystal violet}

The biomass adhered on the inner walls of the wells was quantified by the crystal violet (CV) method according to the procedure described by Stepanovic et al. (2000). The biofilms in the 96-well plates were fixed with $200 \mu \mathrm{l} \mathrm{well}{ }^{-1}$ of $98 \%$ methanol (VWR, Carnaxide, Portugal), for $15 \mathrm{~min}$. Afterwards, the methanol was discarded, the plates left to dry and then the fixed biofilm was stained with $200 \mu \mathrm{l}$ well $^{-1}$ of $\mathrm{CV}$ (Merck KGaA) for $5 \mathrm{~min}$. Excess stain was rinsed out by placing the plate under slow running tap water. After this, the plates were air dried and the dye bound to the adherent cells was resolubilized by adding $200 \mu \mathrm{l} \mathrm{well}^{-1}$ of $33 \%\left(\mathrm{v} \mathrm{v}^{-1}\right)$ glacial acetic acid (Panreac, Cascais, Portugal). The optical density of the solution obtained was measured at $570 \mathrm{~nm}$ using a microtiter plate reader (BioTek, Winooski, VT, USA) and the biofilm mass was presented as $\mathrm{OD}_{570 \mathrm{~nm}}$ values.

\section{Biofilm metabolic activity assessment by resazurin}

Resazurin (7-hydroxy-3H-phenoxazin-3-one-10-oxide) (Sigma-Aldrich) is a viability dye used to assess the metabolic activity of biofilms (Borges et al. 2012). For each biofilm growth period, fresh R2A broth $(190 \mu \mathrm{l})$ was added to the plates. A volume of $10 \mu \mathrm{l}$ of resazurin $(400 \mu \mathrm{M})$ indicator solution was added to each well, in order to obtain a final resazurin concentration of $20 \mu \mathrm{M}$. Plates were incubated in the dark for $3 \mathrm{~h}$ at $25^{\circ} \mathrm{C}$. Fluorescence was measured after excitation at $530 \mathrm{~nm}$ and emission at $590 \mathrm{~nm}$ using a microtiter plate reader (BioTek). The biofilm specific metabolic activity was determined as metabolic activity per biofilm mass and expressed as Fluorescence/ $\mathrm{OD}_{570 \mathrm{~nm}}$.

\section{Monitoring of washed bacterial cells}

For each biofilm growth period, after removing the content of each well from the microtiter plates, $200 \mu \mathrm{l}$ of sterile distilled water were added to remove nonadherent and weakly adherent bacterial cells. Of the $200 \mu \mathrm{l}$ of distilled water, half was then placed in a 
new microtiter plate. The optical density of the solution obtained was measured at $600 \mathrm{~nm}$ using a microtiter plate reader (BioTek) and the results presented as CFU. Standard curves correlating the $\mathrm{OD}_{600 \mathrm{~nm}}$ with CFU were done and the equations $y=1 \times 10^{9} \mathrm{x}$ $-5 \times 10^{6}\left(\mathrm{R}^{2}=0.9949\right)$ and $y=6 \times 10^{8} \mathrm{x}-3 \times 10^{6}$ $\left(\mathrm{R}^{2}=0.9931\right)$ were obtained for A. calcoaceticus and M. oryzae respectively.

\section{Number of bacteria in single and inter- kingdom biofilms}

The number of bacterial cells present in either A. calcoaceticus or $M$. oryzae single species biofilms and in inter-kingdom biofilms was determined in terms of CFU using a plate count assay upon biofilm release. Briefly, bacterial single-species biofilms and interkingdom biofilms were grown in a 96-well plate as described above. After each incubation period, the supernatant was removed, and the plate was washed three times with sterile water. A volume of $200 \mu \mathrm{l}$ of sterile phosphate buffer saline ( $\mathrm{pH} 7.4$ ) was added to each well. Afterwards, biofilms were scrapped with a pipette tip and, in addition, the 96-well plate was covered with the lid and placed into an ultrasonic bath (Bandelin electronic GmbH \& Co. KG, Berlin, Germany). To release bacterial cells from the biofilm, the plate was sonicated for $1 \mathrm{~min}(5 \mathrm{~s}$ sonication, $10 \mathrm{~s}$ interval) at $35 \mathrm{kHz}$. Three replicates were used for each condition and bacterial cells were plated onto R2A agar plates for CFU determination.

\section{Statistical analysis}

Data were analysed applying the two-way analysis of variance (2way ANOVA) and the comparisons between and within experimental groups were carried out using Tukey's multiple comparisons test. The software used for statistical analysis was GraphPad Prism (GraphPad Software, La Jolla, California, USA) version 8.3.0. A $p$-value $<0.05$ was regarded as statistically significant.

\section{Results}

\section{Biofilm mass quantification and specific metabolic activity of biofilms}

The results for $P$. expansum and $M$. oryzae biofilm mass quantification and specific metabolic activity are presented in Figure 1a and $\mathrm{b}$ respectively, whilst results for $P$. expansum and A. calcoaceticus are presented in Figure $2 \mathrm{a}$ and $\mathrm{b}$. In inter-kingdom biofilms, the data feature the global biomass and metabolic activities of both the fungus and the bacteria, not only one specific microorganism. Statistical analysis of the data is shown in Tablse S1 and S2 (Supplemental material).

Regarding single-species biofilms of $P$. expansum, neither patulin nor 3-oxo- $\mathrm{C}_{12}$-HSL influenced their biofilm mass or specific metabolic activity. The singlespecies biofilm mass of $M$. oryzae was reduced at all times in the presence of $25 \mu M$ of patulin $(p<0.05)$. In contrast, both concentrations of 3 -oxo- $\mathrm{C}_{12}$-HSL had a beneficial effect, increasing the biofilm mass of this bacterium (Figure 1a). Despite the effect of both molecules on biofilm mass, the specific metabolic activity of single-species biofilms was not affected (Figure 1b). In inter-kingdom biofilms an increase in biofilm mass was also observed in the presence of 3 -oxo- $\mathrm{C}_{12}-\mathrm{HSL}$, probably due to the increase in the mass of $M$. oryzae. This increase correlated with a decrease in specific metabolic activity. At $72 \mathrm{~h}$, both concentrations of patulin showed an increased metabolic activity of inter-kingdom biofilms in comparison with $P$. expansum biofilms. The results show a slight inhibition of $M$. oryzae towards the fungus for the first $24 \mathrm{~h}$.

Results for A. calcoaceticus single-species biofilms show that neither molecule caused a significant effect on biofilm mass (Figure 2a). However, both concentrations of patulin significantly decreased its specific metabolic activity at $24 \mathrm{~h}$, while $25 \mu \mathrm{M}$ of 3 -oxo- $\mathrm{C}_{12^{-}}$ HSL caused an increase at 48 and $72 \mathrm{~h}$ (Figure 2b). In general, the specific metabolic activity of $A$. calcoaceticus biofilms substantially decreased with time for all conditions. This general decrease is to be expected. Bacteria are more active in the initial growth stages $(24 \mathrm{~h})$ to either adhere to the substratum or to multiply, resembling the log phase of a growth curve. This will eventually culminate in a stationary or death phase, in which metabolic activity is reduced. The presence of $A$. calcoaceticus resulted in a higher inhibition of fungal biofilm formation and development than $M$. oryzae, in particular at 24 and $48 \mathrm{~h}$. However, in the presence of $25 \mu \mathrm{M}$ patulin, this effect was less pronounced, as $P$. expansum was able to form a denser biofilm. In inter-kingdom biofilms, the presence of patulin decreased the specific metabolic activity, while 3-oxo- $\mathrm{C}_{12}$-HSL had no effect at any time point.

\section{Effect of quorum sensing and quenching molecules on bacterial cell density in single species and inter-kingdom biofilms}

The results on the number of bacterial cells, in either single-species biofilms or inter-kingdom biofilms, are 
$\square 24 \mathrm{~h} \square 48 \mathrm{~h} \square 72 \mathrm{~h}$

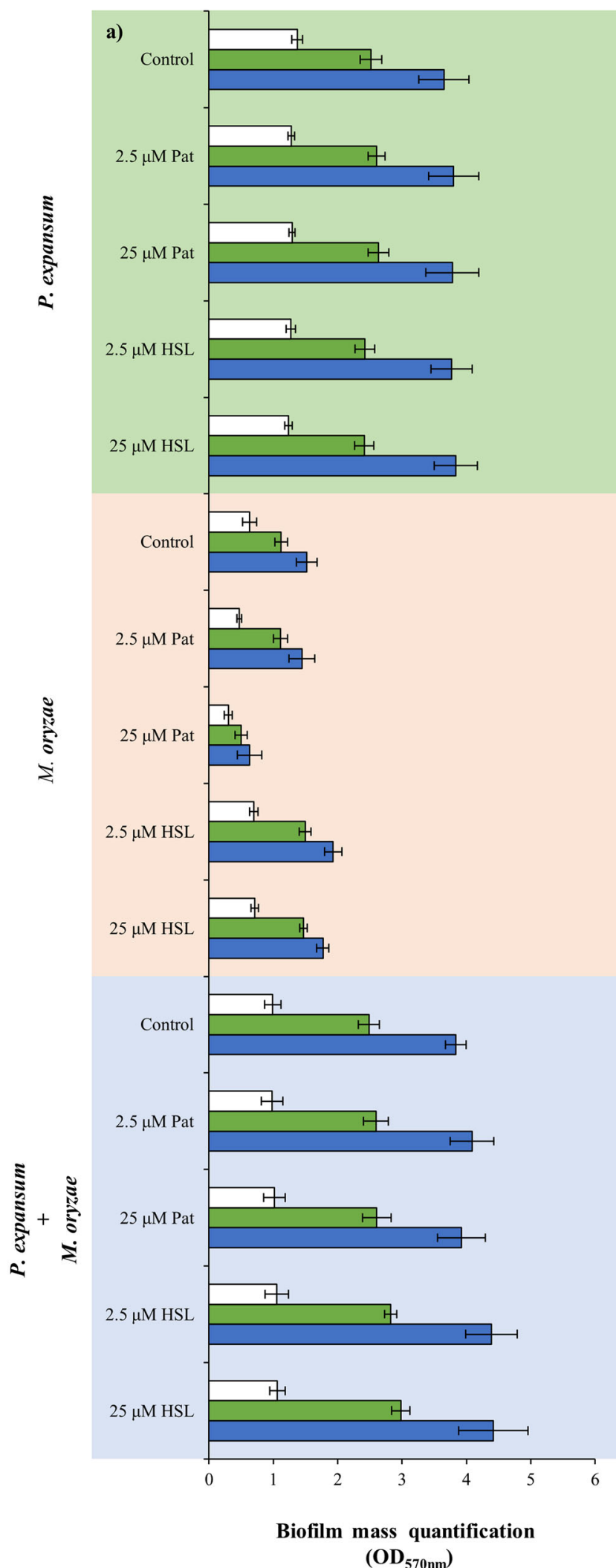

$\square 24 \mathrm{~h} \square 48 \mathrm{~h} \square 72 \mathrm{~h}$

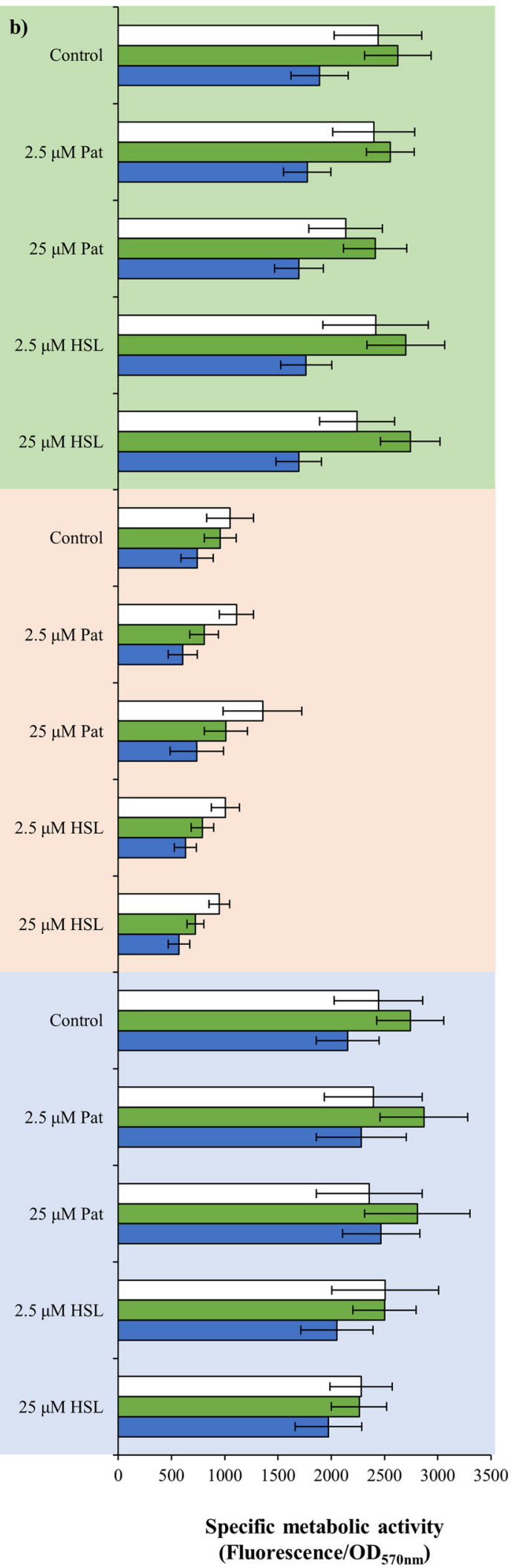

Figure 1. (a) Biofilm mass quantification and (b) specific metabolic activity for single-species and inter-kingdom biofilm formation over time for $P$. expansum and $M$. oryzae. Pat $=$ patulin; $\mathrm{HSL}=3-\mathrm{oxo}_{-} \mathrm{C}_{12}-\mathrm{HSL}$. The means $\pm \mathrm{SDs}$ for at least three independent experiments are illustrated. Each single-species biofilm of $P$. expansum and $M$. oryzae were used as controls against the inter-kingdom biofilms. 
$\square 24 \mathrm{~h} \square 48 \mathrm{~h} \quad \square 72 \mathrm{~h}$

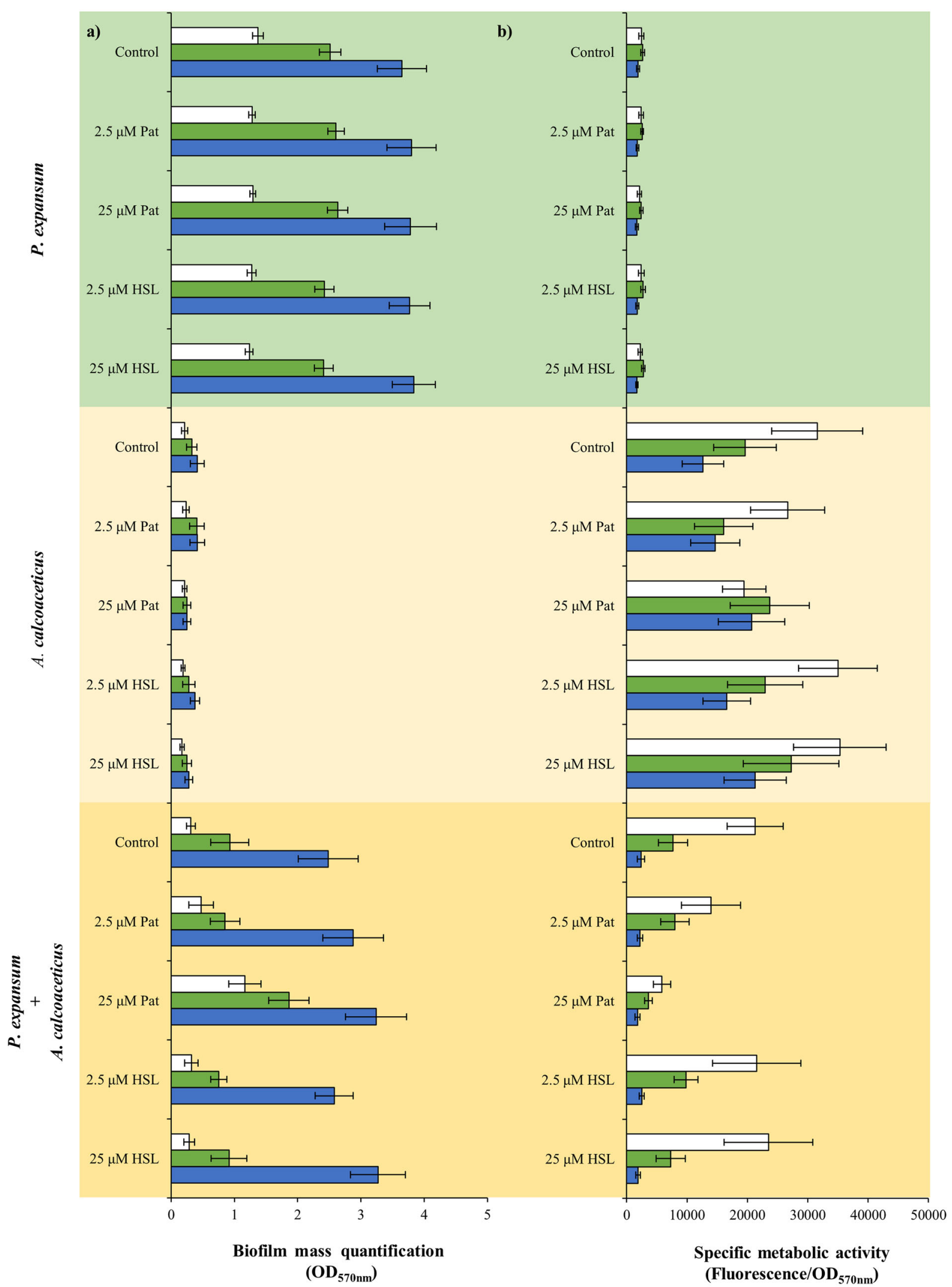

Figure 2. (a) Biofilm mass quantification and (b) specific metabolic activity for single-species and inter-kingdom biofilm formation over time for $P$. expansum and $A$. calcoaceticus. Pat $=$ patulin; $\mathrm{HSL}=3-\mathrm{oxo}_{\mathrm{O}} \mathrm{C}_{12}-\mathrm{HSL}$. The means \pm SDs for at least three independent experiments are illustrated. Each single-species biofilm of $P$. expansum and $A$. calcoaceticus were used as controls against the inter-kingdom biofilms. 


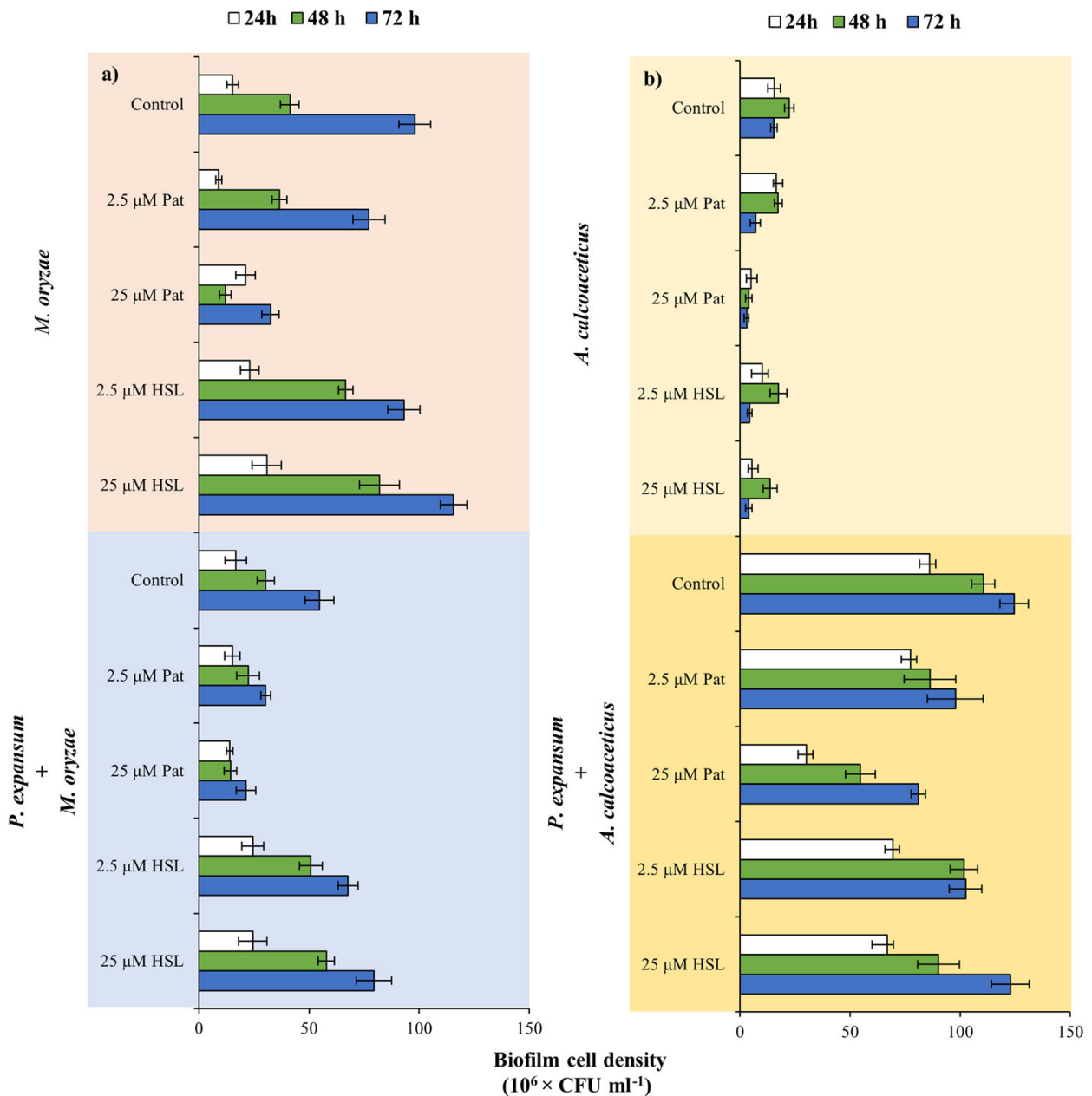

Figure 3. Biofilm cell density for (a) M. oryzae or (b) A. calcoaceticus while forming single-species or inter-kingdom biofilms over time. Pat $=$ patulin; $\mathrm{HSL}=3-0 x-_{12}-\mathrm{HSL}$. The means \pm SDs for two independent experiments are illustrated.

presented in Figure $3 \mathrm{a}$ and $\mathrm{b}$, for $M$. oryzae and $A$. calcoaceticus respectively. Statistical analysis of the data is shown in Tables S3 and S4 (Supplemental material).

Regarding the cell density of $M$. oryzae in singlespecies biofilms, the results correlated with its biofilm mass. Patulin caused a decrease in cell density, specially at $25 \mu \mathrm{M}$, while the presence of both concentrations of 3-oxo- $\mathrm{C}_{12}$-HSL resulted in an increase (Figure 3a). The highest concentration was responsible for a higher increase in cell density. In interkingdom biofilms, an overall reduction was observed in the cell density of $M$. oryzae at 48 and $72 \mathrm{~h}$ when compared with each condition in single-species biofilms. Despite this reduction, the effect of both molecules was similar to that observed in single-species biofilms of $M$. oryzae.

The results for A. calcoaceticus cell density in single-species biofilms reveal significant effects that were not noticeable when analysing the biofilm mass results. A reduction in cell density was observed in the presence of $25 \mu \mathrm{M}$ patulin at all time points (Figure $3 \mathrm{~b}$ ). The presence of 3 -oxo- $\mathrm{C}_{12}$-HSL also caused a reduction in the cell density of this bacterium, specially at the concentration of $25 \mu \mathrm{M}$ and at 24 and $72 \mathrm{~h}$. In inter-kingdom biofilms, the cell densityof A. calcoaceticus was always higher than in single-species biofilms. In relation to the $P$. expansum $+A$. calcoaceticus control, there was a general decrease in the cell density of this bacterium in the presence of both molecules. The highest decrease was observed in the presence of $25 \mu M$ of patulin.

\section{Washed bacterial cells in single-species and inter- kingdom biofilms}

The results on the number of washed bacterial cells, in either single-species or inter-kingdom biofilms, are presented in Figure $4 \mathrm{a}$ and $\mathrm{b}$, for $M$. oryzae and $A$. calcoaceticus respectively. Statistical analysis of the data is shown in Tables S5 and S6 (Supplemental material). 


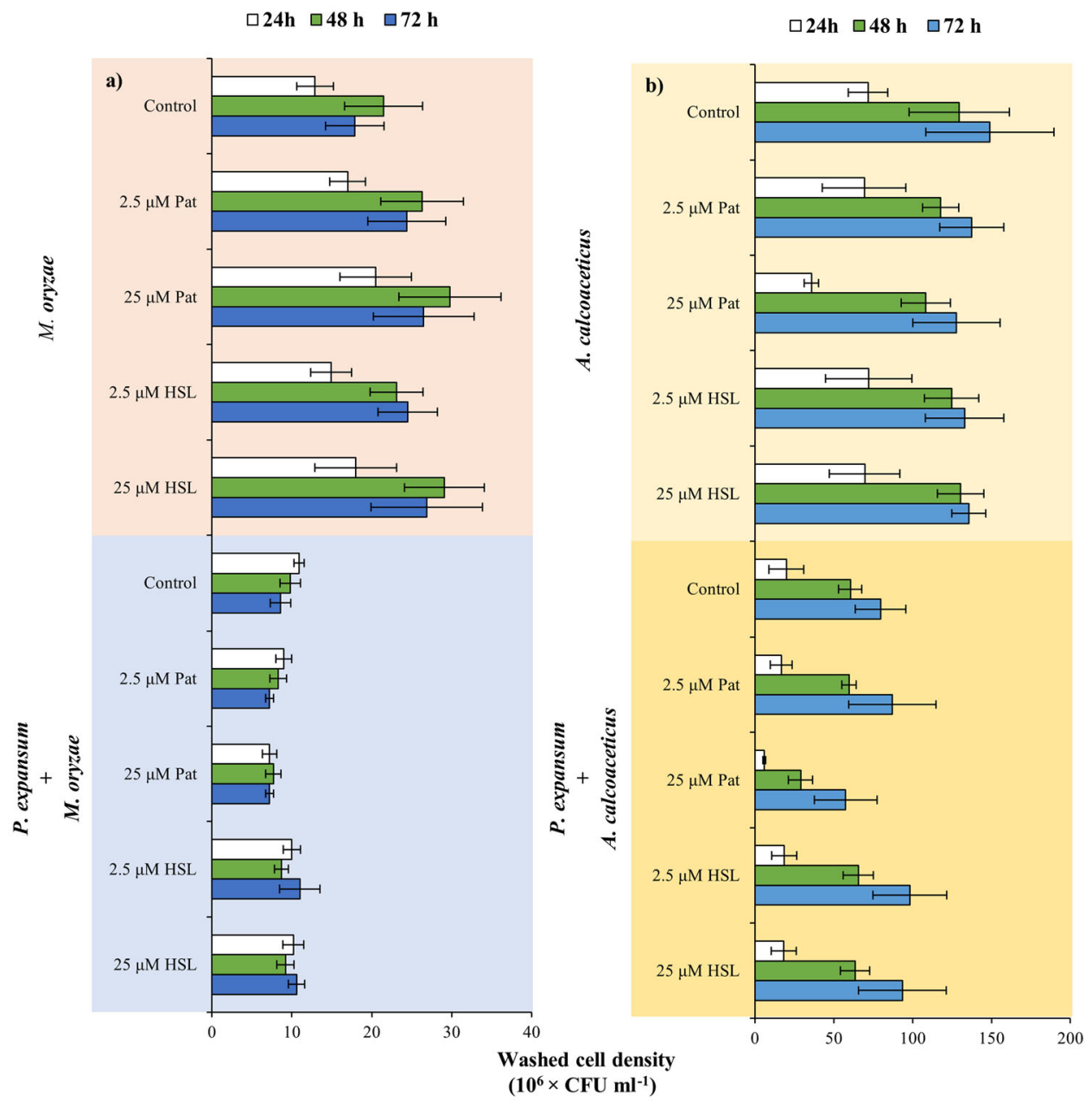

Figure 4. Washed cell density for (a) M. oryzae or (b) A. calcoaceticus while forming single-species or inter-kingdom biofilms over time. Pat = patulin; HSL = 3-oxo- $\mathrm{C}_{12}-\mathrm{HSL}$. The means \pm SDs for two independent experiments are illustrated.

Washed bacterial cells were monitored by CFU. This was done to determine whether the effect of the molecules on the number of cells that were loosely attached to the substratum after removing the planktonic cells was significant. They would not be quantified by $\mathrm{CV}$ as part of the biofilm after the washing steps. With the removal of depleted medium and its renewal, the equilibrium that had been previously maintained was altered with the removal of free-living cells. The results obtained for $M$. oryzae revealed that the presence of the molecules caused an increase in the amount of bacterial cells that were washed out with time. This was more significant with the highest concentration of each molecule. In general, a significant decrease in bacterial CFU was observed in interkingdom biofilms compared with single-species biofilms.

Regarding A. calcoaceticus, the results showed that only $25 \mu \mathrm{M}$ of patulin at $24 \mathrm{~h}$ reduced the number of washed cells in single species biofilms. In inter-kingdom biofilms, the number of A. calcoaceticus washed cells was inferior compared with single-species biofilms.

\section{Discussion}

The present study reports the effect of patulin and 3oxo- $\mathrm{C}_{12}$-HSL on single and inter-kingdom biofilm formation and development by $P$. expansum and two bacteria, A. calcoaceticus and M. oryzae. These microorganisms were chosen based on different characteristics: their ability to form mature single-species biofilms between 48 and $72 \mathrm{~h}$ growth, and because they have been assessed while forming inter-kingdom biofilms (Simões et al. 2010; 2015; Afonso et al. 2019). P. expansum, in particular, was also selected due to its well-known ability to produce patulin as a secondary metabolite (Santos et al. 2002; Reddy et al. 2010; De Clercq et al. 2016). However, it produces this mycotoxin in certain favourable conditions (i.e. an appropriate medium and longer periods of incubation time). In the medium used in this study, and for 
its shorter duration, no detectable amounts of this toxin were produced (data not shown). For this reason, there was a need to add the mycotoxin in the medium throughout the duration of the experiment. Biofilm formation and development of this filamentous fungus was not affected by the exogenous presence of patulin. At the concentrations used in this work, 3-oxo- $\mathrm{C}_{12}$-HSL did not influence $P$. expansum biofilm formation. To date, the effect of this compound on filamentous fungi has not been studied.

The bacteria used in this study are Gram-negative and representative of drinking water bacteria. In addition, 3-oxo- $\mathrm{C}_{12}$-HSL has been found in Acinetobacter (Bhargava et al. 2010) and Methylobacterium species (Pomini et al. 2009). In a previous study, both the species used presently were screened for the presence of AHLs. Small and long side chained AHLs were detected in $M$. oryzae while no AHLs were detected in A. calcoaceticus (Simões et al. 2007a). The absence of the production of AHLs in A. calcoaceticus in this study could be related to the medium composition, suggesting that the QS molecules produced could be modulated by culture medium conditions (González et al. 2001). Besides their biofilm formation ability, these were the reasons to include both bacteria in this study. The single-species biofilm mass of $M$. oryzae showed a correlation with the CFU of this bacterium. Patulin at the highest concentration tested in this work caused a decrease in both biofilm mass and $\mathrm{CFU}$, while 3-oxo- $\mathrm{C}_{12}$-HSL caused an increase. The highest concentration of 3-oxo- $\mathrm{C}_{12}$-HSL was, in general, responsible for the highest increase in CFU. In inter-kingdom biofilms, the effect of the molecules on $M$. oryzae followed the same pattern as for single-species biofilms. The decrease in the cell density of planktonic $M$. oryzae cells as well as in biofilms in the presence of $P$. expansum, reveals that the presence of this fungus caused a slight inhibition towards this bacterium. Despite no amounts of patulin being detected, there might be a small quantity being produced, or other molecules and/or other quorum quenching mechanisms that could hinder the M. oryzae QS mechanism.

In $A$. calcoaceticus single-species biofilms, it was shown that neither patulin nor the QS molecule had a significant effect on biofilm mass despite a slight decrease with $25 \mu \mathrm{M}$ patulin. However, looking at the CFU of this bacterium, a significant reduction was observed in the presence of the same concentration of this molecule. Specific metabolic activity was also reduced in the first $24 \mathrm{~h}$ of biofilm formation in the presence of $25 \mu \mathrm{M}$ patulin, indicating that this compound may act on the metabolic activity of this bacterium. In contrast to the effect on M. oryzae, the QS molecule did not cause an increase in either the biofilm mass or the CFU of $A$. calcoaceticus. As mentioned above, the absence of AHLs in A. calcoaceticus and their presence in $M$. oryzae may explain this difference (Simões et al. 2007a). In inter-kingdom biofilms with $P$. expansum, the CFU for $A$. calcoaceticus increased significantly for all conditions when compared with single-species biofilms. In contrast, the reduction in CFU when analysing the washed cells in the presence of the fungus reveals a protection effect of the fungus towards this bacterium. This biotic support and protection offered by intertwined fungal hyphae, in addition to the ability of $A$. calcoaceticus to coaggregate, confers an advantage on this bacterium to proliferate (Simões et al. 2008; Frey-Klett et al. 2011). Patulin, in comparison with the effect on the CFU of this bacterium in single-species biofilms, also caused a reduction in inter-kingdom biofilms, especially at $25 \mu \mathrm{M}$. However, the number of CFU of $A$. calcoaceticus in inter-kingdom biofilms, was still higher than in any condition for single-species biofilms. These results emphasize the protection and biotic support that the fungal hyphae confer towards this bacterium. Analysing the effect of A. calcoaceticus on $P$. expansum biofilm formation, an inhibition was detected towards the fungus, especially at 24 and $48 \mathrm{~h}$. Similar results were observed in other studies where bacteria inhibited fungal spore germination and hyphal growth (Mowat et al. 2010; Afonso et al. 2019; Kousser et al. 2019; Nogueira et al. 2019). With the removal of planktonic cells and the renewal of the medium, viability and fungal growth increased over time as seen by the increase in biofilm mass. Nogueira et al. (2019) showed that Aspergillus species remain viable upon interaction with Klebsiella pneumoniae. The initial inhibitory effect may be due to direct competition for nutrients, the production of metabolites that might inhibit fungal development, the higher growth rate and metabolic activity of the bacteria or a combination of these factors (Mowat et al. 2010; Nogueira et al. 2019). As the presence of $25 \mu \mathrm{M}$ patulin causes a reduction in the metabolic activity and CFU of $A$. calcoace, it might be the reason for the increase in fungal biofilm mass in interkingdom biofilms.

The effect of both molecules had, as expected, opposite effects. Patulin has been a known QSI. Using DNA micro-array-based transcriptomics, Rasmussen et al. (2005b) showed that patulin down-regulates QSregulated genes in Pseudomonas aeruginosa by 45\%, 
indicating that it shows specificity for QS-regulated gene expression. More recently, it has also been shown that patulin interferes with the ATP binding cassette transporter of another QS signalling molecule, the auntoinducer-2, in Salmonella enterica serovar Typhi (Vijayababu et al. 2018). A high reduction in the biofilm forming ability and QS signalling system of Halomonas pacifica was also reported in the presence of $25 \mu \mathrm{M}$ patulin (Liaqat et al. 2014). However, studies conducted on biofilm formation by different isolates from dental unit water lines have shown the opposite effect. Concentrations up to $25 \mu \mathrm{M}$ of this compound promoted biofilm formation by Bacillus cereus, $P$. aeruginosa and Achromobacter sp. (Liaqat et al. 2008; 2010). These reports, in combination with the present results, indicate that the patulin effect on biofilm formation is species dependent.

The increase in biofilm formation in the presence of 3-oxo- $\mathrm{C}_{12}$-HSL is in accordance with other studies. Bhargava et al. (2012) showed that an exogenous concentration of $20 \mu \mathrm{M}$ of this molecule was responsible for a significant increase in biofilm formation by Acinetobacter baumannii and $P$. aeruginosa. In a study on the changes in Salmonella enterica phenotypes in the presence of AHLs, it was observed that 3-oxo- $\mathrm{C}_{12}$-HSL, although at lower concentrations $(50 \mathrm{nM})$, caused an increase in biofilm formation and promoted the expression of biofilm formation genes (Campos-Galvão et al. 2016). However, 3-oxo- $\mathrm{C}_{12^{-}}$ HSL at $50 \mu \mathrm{M}$ significantly supressed Legionella pneumoniae biofilm formation (Kimura et al. 2009). These results indicate that 3 -oxo- $\mathrm{C}_{12}$-HSL plays a role in intraspecies communication and also in inter-kingdom interactions.

In conclusion, the results show that, in general and under laboratory conditions, P. expansum biofilm formation and development was not affected by the exogenous presence of either patulin or 3-oxo- $\mathrm{C}_{12^{-}}$ HSL at the concentrations tested. M. oryzae biofilm formation and development were more affected by the presence of these molecules than A. calcoaceticus. In inter-kingdom growth, the cell density of $M$. ory$z a e$ was generally lower than in single-species growth which indicates a detrimental effect of the fungus towards this bacterium. However, the increase in the cell desnity of $A$. calcoaceticus in inter-kingdom growth is an indication of the physical protection that the fungus provide to this opportunistic bacterium. The present study finds that inter-kingdom biofilm formation and development is highly species-specific. Opportunistic bacteria such as A. calcoaceticus may benefit from the presence of the fungus whereas $M$. oryzae does not. Quorum sensing and quenching molecules have a significant effect in inter-kingdom biofilm formation and especially on bacterial numbers. Moreover, a possible protection role that filamentous fungi may provide to opportunistic bacteria in complex biofilms is reported.

\section{Disclosure statement}

No conflict of interest was reported by the author(s).

\section{Funding}

Tiago B. Afonso acknowledges the grant provided by the Portuguese Foundation for Science and Technology (FCT) under grant no. PD/BD/128033/2016. Furthermore, this study was also supported by FCT under the scope of the strategic funding of UIDB/04469/2020 unit and BioTecNorte operation (NORTE-01-0145-FEDER-000004) funded by the European Regional Development Fund under the scope of Norte2020 - Programa Operacional Regional do Norte.

\section{References}

Afonso TB, Simões LC, Lima N. 2019. In vitro assessment of inter-kingdom biofilm formation by bacteria and filamentous fungi isolated from a drinking water distribution system. Biofouling. 35:1041-1054. doi:10.1080/ 08927014.2019 .1688793

Antunes LC, Ferreira RB, Buckner MM, Finlay BB. 2010. Quorum sensing in bacterial virulence. Microbiology (Reading). 156:2271-2282. doi:10.1099/mic.0.038794-0

Bhargava N, Sharma P, Capalash N. 2010. Quorum sensing in Acinetobacter: an emerging pathogen. Crit Rev Microbiol. 36:349-360. doi:10.3109/1040841X.2010. 512269

Bhargava N, Sharma P, Capalash N. 2012. N-acyl homoserine lactone mediated interspecies interactions between $A$. baumannii and $P$. aeruginosa. Biofouling. 28:813-822. doi:10.1080/08927014.2012.714372

Borges A, Saavedra MJ, Simões M. 2012. The activity of ferulic and gallic acids in biofilm prevention and control of pathogenic bacteria. Biofouling. 28:755-767. doi:10. 1080/08927014.2012.706751

Bryers JD, Ratner BD. 2004. Bioinspired implant materials befuddle bacteria. ASM News. 70:232-237.

Campos-Galvão ME, Ribon AO, Araújo EF, Vanetti MC. 2016. Changes in the Salmonella enterica Enteritidis phenotypes in presence of acyl homoserine lactone quorum sensing signals. J Basic Microbiol. 56:493-501. doi:10. 1002/jobm.201500471

Churchill MEA, Chen L. 2011. Structural basis of acylhomoserine lactone-dependent signaling. Chem Rev. 111: 68-85. doi:10.1021/cr1000817

De Clercq N, Vlaemynck G, Van Pamel E, Colman D, Heyndrickx M, Van Hove F, De Meulenaer B, Devlieghere F, Van Coillie E. 2016. Patulin production 
by Penicillium expansum isolates from apples during different steps of long-term storage. World Mycotoxin J. 9: 379-388. doi:10.3920/WMJ2015.1936

Douterelo I, Jackson M, Solomon C, Boxall JB. 2016. Microbial analysis of in situ biofilm formation in drinking water distribution systems: implications for monitoring and control of drinking water quality. Appl Microbiol Biotechnol. 100:3301-3311. doi:10.1007/ s00253-015-7155-3

Douterelo I, Calero-Preciado C, Soria-Carrasco V, Boxall JB. 2018. Whole metagenome sequencing of chlorinated drinking water distribution systems. Environ Sci: Water Res Technol. 4:2080-2091. doi:10.1039/C8EW00395E

Feazel LM, Baumgartner LK, Peterson KL, Frank DN, Harris JK, Pace NR. 2009. Opportunistic pathogens enriched in showerhead biofilms. Proc Natl Acad Sci USA. 106:16393-16399. doi:10.1073/pnas.0908446106

Fernandes S, Simões LC, Lima N, Simões M. 2019. Adhesion of filamentous fungi isolated from drinking water under different process conditions. Water Res. 164: 114951 doi:10.1016/j.watres.2019.114951

Flemming HC, Percival SL, Walker JT. 2002. Contamination potential of biofilms in water distribution systems. Water Sci Technol Water Supply. 2:271-280. doi:10.2166/ws.2002.0032

Frey-Klett P, Burlinson P, Deveau A, Barret M, Tarkka M, Sarniguet A. 2011. Bacterial-fungal interactions: hyphens between agricultural, clinical, environmental, and food microbiologists. Microbiol Mol Biol Rev. 75:583-609. doi:10.1128/MMBR.00020-11

Gonçalves AB, Paterson RM, Lima N. 2006. Survey and significance of filamentous fungi from tap water. Int J Hyg Environ Health. 209:257-264. doi:10.1016/j.ijheh.2005.12. 001

González RH, Nusblat A, Nudel BC. 2001. Detection and characterization of quorum sensing signal molecules in Acinetobacter strains. Microbiol Res. 155:271-277. doi:10. 1016/S0944-5013(01)80004-5

González JE, Keshavan ND. 2006. Messing with bacterial quorum sensing. Microbiol Mol Biol Rev. 70:859-875. doi:10.1128/MMBR.00002-06

Jones JBG. 1994. Fungal adhesion. Mycol Res. 98:961-981. doi:10.1016/S0953-7562(09)80421-8

Kimura S, Tateda K, Ishii Y, Horikawa M, Miyairi S, Gotoh N, Ishiguro M, Yamaguchi k. 2009. Pseudomonas aeruginosa Las quorum sensing autoinducer suppresses growth and biofilm production in Legionella species. Microbiology (Reading). 155:1934-1939. doi:10.1099/mic. 0.026641-0

Kousser C, Clark C, Sherrington S, Voelz K, Hall RA. 2019. Pseudomonas aeruginosa inhibits Rhizopus microsporus germination through sequestration of free environmental iron. Sci Rep. 9:5714. doi:10.1038/s41598-019-42175-0

Li X, Wang W, Hu C, Yang M, Hu H, Niu J. 2015. Characteristics of biofilms and iron corrosion scales with ground and surface waters in drinking water distribution systems. Corros Sci. 90:331-339. doi:10.1016/j.corsci. 2014.10.028

Liaqat I, Bachmann RT, Sabri AN, Edyvean RGJ, Biggs CA. 2008. Investigating the effect of patulin, penicillic acid and EDTA on biofilm formation of isolates from dental unit water lines. Appl Microbiol Biotechnol. 81:349-358. doi:10.1007/s00253-008-1691-Z

Liaqat I, Bachmann RT, Sabri AN, Edyvean RGJ. 2010. Isolate-specific effects of patulin, penicillic acid and EDTA on biofilm formation and growth of dental unit water line biofilm isolates. Curr Microbiol. 61:148-156. doi:10.1007/s00284-010-9591-8

Liaqat I, Bachmann RT, Edyvean RGJ. 2014. Type 2 quorum sensing monitoring, inhibition and biofilm formation in marine microorganisms. Curr Microbiol. 68: 342-351. doi:10.1007/s00284-013-0484-5

Mowat E, Rajendran R, Williams C, McCulloch E, Jones B, Lang S, Ramage G. 2010. Pseudomonas aeruginosa and their small diffusible extracellular molecules inhibit Aspergillus fumigatus biofilm formation. FEMS Microbiol Lett. 313:96-102. doi:10.1111/j.1574-6968.2010.02130.x

Nogueira M, Pereira L, Jenull S, Kuchler K, Lion T. 2019. Klebsiella pneumoniae prevents spore germination and hyphal development of Aspergillus species. Sci Rep. 9:218. doi:10.1038/s41598-018-36524-8

Papenfort K, Bassler B. 2016. Quorum sensing signalresponse systems in Gram-negative bacteria. Nat Rev Microbiol. 14:576-588. doi:10.1038/nrmicro.2016.89

Paterson RRM, Kelley J, Gallagher M. 1997. Natural occurrence of aflatoxins and Aspergillus flavus (Link) in water. Lett Appl Microbiol. 25:435-436. doi:10.1111/j.1472765x.1997.tb00012.x

Paterson RRM, Lima N. 2005. Fungal contamination of drinking water. In: Lehr J, Keeley J, Lehr J, Kingery TB III, editors. Water encyclopedia: the water quality and resource development. New York (NY): Wiley; p. $1-7$.

Pomini AM, Cruz PLR, Gai C, Araújo WL, Marsaioli AJ. 2009. Long-chain acyl-homoserine lactones from Methylobacterium mesophilicum: synthesis and absolute configuration. J Nat Prod. 72:2125-2129. doi:10.1021/ np900043j

Rasmussen TB, Skindersoe ME, Bjarnsholt T, Phipps RK, Christensen KB, Jensen PO, Andersen JB, Koch B, Larsen TO, Hentzer M, et al. 2005a. Identity and effects of quorum-sensing inhibitors produced by Penicillium species. Microbiology (Reading). 151:1325-1340. doi:10. 1099/mic.0.27715-0

Rasmussen TB, Bjarnsholt T, Skindersoe ME, Hentzer M, Kristoffersen P, Köte M, Nielsen J, Eberl L, Givskov M. 2005b. Screening for quorum-sensing inhibitors (QSI) by use of a novel genetic system, the QSI selector. J Bacteriol. 187:1799-1814. doi:10.1128/JB.187.5.1799-1814. 2005

Reddy KR, Spadaro D, Lore A, Gullino ML, Garibaldi A. 2010. Potential of patulin production by Penicillium expansum strains on various fruits. Mycotoxin Res. 26: 257-265. doi:10.1007/s12550-010-0064-5

Santos IM, Abrunhosa L, Venâncio A, Lima N. 2002. The effect of culture preservation techniques on patulin and citrinin production by Penicillium expansum Link. Lett Appl Microbiol. 35:272-275. doi:10.1046/j.1472-765x. 2002.01186.x

Saurav K, Borbone N, Burgsdorf I, Teta R, Caso A, BarShalom R, Esposito G, Britstein M, Steindler L, Costantino V. 2020. Identification of quorum sensing 
activators and inhibitors in the marine sponge sarcotragus spinosulus. Mar Drugs. 18:1-14.

Simões LC, Simões M, Vieira MJ. 2007a. Biofilm interactions between distinct bacterial genera isolated from drinking water. Appl Environ Microbiol. 73:6192-6200. doi:10.1128/AEM.00837-07

Simões LC, Simões M, Oliveira R, Vieira MJ. 2007b. Potential of the adhesion of bacteria isolated from drinking water to materials. J Basic Microbiol. 47:174-183. doi:10.1002/jobm.200610224

Simões LC, Simões M, Vieira MJ. 2008. Intergeneric coaggregation among drinking water bacteria: evidence of a role for Acinetobacter calcoaceticus as a bridging bacterium. Appl Environ Microbiol. 74:1259-1263. doi:10.1128/AEM.01747-07

Simões LC, Simões M, Vieira MJ. 2010. Influence of the diversity of bacterial isolates from drinking water on resistance of biofilms to disinfection. Appl Environ Microbiol. 76:6673-6679. doi:10.1128/AEM.00872-10

Simões LC, Simões M, Lima N. 2015. Kinetics of biofilm formation by drinking water isolated Penicillium expansum. Biofouling. 31:349-362. doi:10.1080/08927014.2015. 1042873

Siqueira VM, Oliveira HMB, Santos C, Paterson RRM, Gusmão NB, Lima N. 2013. Biofilms from a Brazilian water distribution system include filamentous fungi. Can J Microbiol. 59:183-188. doi:10.1139/cjm-2012-0529
Shrout JD, Tolker-Nielsen T, Givskov M, Parsek MR. 2011. The contribution of cell-cell signaling and motility to bacterial biofilm formation. MRS Bull. 36:367-373. doi: $10.1557 / \mathrm{mrs} .2011 .67$

Stepanović S, Vuković D, Dakić I, Savić B, Švabić-Vlahović M. 2000. A modified microtiter-plate test for quantification of staphylococcal biofilm formation. J Microbiol Methods. 40:175-179. doi:10.1016/S0167-7012(00)001226

Wang H, Zhu Y, Hu C. 2017. Impacts of bacteria and corrosion on removal of natural organic matter and disinfection byproducts in different drinking water distribution systems. Int Biodeterior Biodegradation. 117: 52-59. doi:10.1016/j.ibiod.2016.11.023

Vijayababu P, Samykannu G, Antonyraj CB, Thomas J, Narayanan SB, Basheer Ahamed SI, Piramanayagam S. 2018. Patulin interference with ATP binding cassette transferring auto inducer -2 in Salmonella typhi and biofilm inhibition via quorum sensing. Informatics Med Unlocked. 11:9-14. doi:10.1016/j.imu.2018.02.001

Zhou X, Zhang K, Zhang T, Li C, Mao X. 2017. An ignored and potential source of taste and odor (T\&O) issues-biofilms in drinking water distribution system (DWDS). Appl Microbiol Biotechnol. 101:3537-3550. doi:10.1007/ s00253-017-8223-7 